\title{
UMA REFLEXÃO SOBRE A INTELECTUALIDADE CATÓLICA
}

\author{
Marcos Gonçalves
}

A obra do historiador Cândido Moreira Rodrigues é uma contribuição recente ao debate historiográfico que almeja compreender as interações entre o pensamento católico e a cultura política no Brasil republicano. A publicação é fruto de dissertação de mestrado defendida pelo autor na Universidade Estadual Paulista (Unesp) e tem a seu favor o continuado estímulo que a instituição dedica às produções germinadas nos seus cursos de pós-graduação, seja em âmbito de mestrado, seja em âmbito de doutorado. Com a análise detida em séries temáticas da revista A Ordem, entre meados das décadas de 1930 e 1940, Rodrigues ajuda a ampliar o quadro de questões associadas a um período determinado do movimento chamado de "restauração católica", espécie de esforço generalizado empreendido pelos católicos em vários campos da política e da cultura para garantir à Igreja maior presença e influência na sociedade. O advento do Estado varguista, nos anos 1930, propiciou ao movimento de restauração angariar êxitos, não somente a partir de concessões constitucionais em 1934, mas também ao costurar alianças com as elites dirigentes do país em troca de benefícios materiais e simbólicos. Como um dos pontos de partida da "restauração", o intelectual Jackson de Figueiredo, convertido ao catolicismo em 1918, fundou em 1921, a revista A Ordem. Além de traduzir uma parte da experiência dos católicos leigos na cenografia da restauração, a revista, conforme a ótica de Rodrigues na justificativa introdutória, constituiuse em órgão de difusão das propostas de reordenação do país nos moldes cristãos. Os intelectuais agregados em torno d'A Ordem passaram a considerar-se o único segmento da sociedade capaz de oferecer respostas aos problemas nacionais e a imprimir novos rumos ao país (RODRIGUES, 2005, p. 16).

Pelo fato de A Ordem ser um órgão vinculado categoricamente à imprensa católica e responder aos propósitos conjugados da hierarquia eclesiástica e da intelectualidade leiga, antes de destacar as opções teóricas e metodológicas, ou ainda, o percurso empírico construído por Rodrigues, é necessário tecer breves comentários sobre a importância da comunicação social católica no projeto de "restauração". Cabe assinalar de passagem uma literatura específica direcionada a avaliar o papel da revista A Ordem e de outros meios de comunicação católicos. Desde pelo menos 1890, com a separação do novo Estado republicano e Igreja, a hierarquia católica, por meio de cartas pastorais, tratou de incentivar métodos de atuação da imprensa confessional que viessem ao encontro de uma atitude crítica à sociedade posterior ao Império e defensora dos interesses da religião hegemônica. Tais ações visavam a acentuar a oposição à chamada imprensa “ímpia” e apresentavamse como forma de combate a certas configurações jurídicas outorgadas pela República à sociedade política em alguns de seus aspectos marcantes: o seu viés não confessional, a liberdade religiosa, o laicismo na educação. Talvez a primeira manifestação reativa do projeto católico frente à situação inaugurada pela República tenha sido a Pastoral Coletiva dos Bispos do Brasil, lavrada em 1890. Nesse documento, o líder do episcopado brasileiro à época, Dom Antonio Macedo Costa, pregava como condição indispensável à reordenação institucional do catolicismo o zelo pelo desenvolvimento e pela difusão da "boa imprensa". Foi a partir dessa Pastoral que então se verificou uma série de tentativas, muitas delas frustradas, para ampliar o número de revistas e de jornais católicos e reafirmar a imprensa como um canal privilegiado a fim de rebater as idéias que fugiam aos princípios doutrinários do catolicismo ortodoxo.

Vários pesquisadores mostraram-se atentos ao fenômeno. Assim é que, nas reflexões sobre o processo de “construção institucional” (MICELI, 1988) ${ }^{1}$ da Igreja Católica na era republicana, não há como renunciar ao

\footnotetext{
1 “Construção institucional” foi o termo, bastante adequado ao nosso ver, utilizado por Sérgio Miceli para caracterizar uma “nova era” no percurso da Igreja católica no Brasil. Refere-se, em linhas gerais, ao período (1890-1930) de florescimento, liberdade de ação, proselitismo, expansão que vive o catolicismo institucional no Brasil. Agregue-se a isso o notável crescimento das ordens religiosas estrangeiras.
} 
trabalho de redescoberta do papel fundamental dos meios de comunicação. Sem a necessidade de recuar em demasia no tempo, lembramos a densidade de trabalhos de Veloso (1978) e Cordi (1984) sobre a revista $A$ Ordem, com ênfase no pensamento tradicional e contra-revolucionário do seu fundador. Mais recentemente, Dias (1996) e Beired (1999) apropriaram-se de alguns temas d'A Ordem, interessados, respectivamente, na forma como se constituiu uma doutrina da autoridade e na problemática de uma história comparada de intelectuais autoritários no Brasil e na Argentina. Também Almeida (2002) desenvolveu tese sobre a revista Vozes de Petrópolis, editada pela Ordem dos Franciscanos, destacando o corpo de doutrinas autoritárias que permeava a política editorial da revista, quando o assunto era o imaginário da cinematografia. De modo geral, nota-se nesses trabalhos que o catolicismo aparece, ou reaparece, como fato cultural, político e cotidiano, inquirido pela historiografia em suas mais penetrantes capacidades simbólicas. De fato, os estudos sobre a fenomenologia do catolicismo não emergem apenas como substrato teológico inalcançável para leigos ou mesmo como algo infenso ao conflito social. Ao longo das três últimas décadas, dado o crescente interesse acadêmico por temas relacionados aos binômios religião e sociedade ou religião e cultura, desfez-se completamente uma possível idéia de que conferiria aos especialistas circunscritos às esferas do confessional ou do teológico o monopólio de saber sobre o desempenho do catolicismo, sobre a história da Igreja, sobre a representatividade do laicato ou sobre as práticas devocionais dos fiéis 2 . É oportuno ainda lembrar, como podemos notar, o notável fôlego proporcionado pela revista $A$ Ordem enquanto fonte de investigação histórica, colocando-se como objeto de estudo para análise de uma miríade de categorias. Esse argumento é tão procedente que os 552 artigos selecionados pelo autor do trabalho aqui resenhado são legíveis sob o prisma cultural, político e, claro está, religioso (RODRIGUES, 2005, p. 21). O mérito inicial da pesquisa, no entanto, é a proposta de articulação que envolve as três modalidades citadas. Por esse viés, é possível entender que a produção intelectual da revista mergulha em uma ampla tradição de textos a serem designados como cânones que embasam sua concepção editorial, e legitimam seu projeto de existência. Rodrigues interessa-se por demarcar desde o final do século XVIII quais os textos e quais os teóricos protagonistas de uma determinada linhagem ideológica que teriam sido marcos de referência aos intelectuais que escreviam para $A$ Ordem na cronologia escolhida. Em síntese: que sistemas de pensamento ou corrente de idéias estariam a nortear a trajetória da revista no período analisado? Podem-se admitir quebras ou descontinuidades no projeto ideológico da revista?

Rodrigues distingue duas espécies de matrizes inspiradoras dos intelectuais d’A Ordem: político-ideológicas e teórico-filosóficas. Sob a primeira matriz, reúnem-se teóricos contra-revolucionários como Edmund Burke, autor da clássica obra Reflexões sobre a revolução em França, crítica de primeira hora da Revolução Francesa. Na mesma direção agrupar-se-iam pensadores católicos, como os franceses Louis Ambroise De Bonald (17541840) e Joseph De Maistre (1753-1821) e o espanhol Juan Donoso Cortés (1809-1853). Idealizadores de uma arquitetura política conservadora que toca mesmo a reivindicação por uma sociedade teocrática, converge em suas ideologias a denúncia dos princípios formais da igualdade democrática e da soberania popular. Aliás, Romano (1994), ao comentar a doutrina desses teóricos, foi preciso quando identificou no conservadorismo uma conexão com o papel dado ao conceito de soberania. Não é a percepção sobre uma concepção obsoleta e oposta às modernidades técnicas a chave para definir-se um pensamento político como conservador e, sim, compreender, entre outros sinais, a atitude de completa rejeição diante da soberania popular e dos sistemas de representação política que têm como alicerce a instituição parlamentar. Se para Burke, teórico da contrarevolução, problemas de profundidade como a subversão e o ateísmo eram intrínsecos aos movimentos revolucionários, observa-se nos pensadores franceses a sistemática defesa da harmonia de altar e trono, do que se infere a possibilidade de um Estado monárquico confessional (De Bonald). Essa partilha de poder entre o temporal e o espiritual é ressonância ou quase uma reedição da "capacidade dual” descrita por Kantorowicz (1998), em que alguns bispos durante o feudalismo não só eram príncipes da Igreja, mas também vassalos do rei. No pensamento contra-revolucionário de De Bonald, o papel de conservação da sociedade seria atribuído à religião cristã (catolicismo) e à monarquia ou, como salienta Rodrigues (2005, p. 42): "De Bonald entendia que era através do poder atribuído por Deus a um homem, o monarca, que a dominação exercida sobre a sociedade ganhava legitimidade”. Com as Considérations sur la France, texto escrito em 1797 por Joseph De Maistre,

2 Atualmente, também estão em desenvolvimento no curso de doutoramento em História da Universidade Federal do Paraná, teses que têm como objeto ou como fonte de investigação a imprensa católica. Lembramos aqui o estudo do historiador Samuel Klauck, sobre a revista da Ordem dos Jesuítas Skt. Paulusblatt, editada nas colônias alemãs do Rio Grande do Sul; e a nossa própria pesquisa que tem como uma de suas fontes principais a revista católica popular Ave Maria, editada em São Paulo pelos padres claretianos e de circulação nacional desde princípios do século XX. 
temos, segundo Rodrigues, um "marco do pensamento conservador e contra-revolucionário” (idem, p. 51), com a veemente negação da (necessidade de) existência de uma constituição política baseada na deliberação popular. Mais além, com seu Du Pape (1819), De Maistre defende a idéia de um governo teocrático. Ele enxergava na Igreja um papel de salvadora da humanidade. A ela era conferida uma natureza divina e, obviamente, exterior à razão humana. Já no pensamento do espanhol Donoso Cortés é exacerbado o discurso contra o liberalismo e o socialismo. A ideologia liberal, na visão de Cortés, "funda suas bases sobre a efetiva negação de dois princípios básicos do catolicismo, que são o pecado original e a atuação da providência nas coisas humanas" (idem, p. 71). Também no célebre Ensayo sobre el Catolicismo, el Liberalismo y el Socialismo de 1851, Cortés evoca a famosa imagem do Anticristo na figura ideológica do socialismo. Aliás, dada a emergência do liberalismo e do socialismo nas representações da política no século XIX e ainda a grave ameaça significada pelo espraiar da idéia comunista que negava a existência de Deus, vaticina Cortés: "a personificação da sociedade na forma de um único governo ou de um único indivíduo - despótico - o que não tardaria a ocorrer, no século XX, mais precisamente nas personificações de Stalin, Mussolini, Hitler, Vargas etc. - obviamente que os três últimos não na ótica do comunismo" (idem, p. 72).

Na avaliação de Rodrigues, três autores contemporâneos edificam por meio de graus variáveis de influência, as “matrizes teórico-filosóficas” da revista A Ordem: Carl Schmitt (1888-1985), Henri Bergson (1859-1941) e Jacques Maritain (1882-1972). É evidente que a escolha por Schmitt deve-se muito ao contexto histórico em que a análise inscreve-se. Ora, como um teórico que não esconde a simpatia pelo nazismo, Schmitt parte de uma reflexão que acirra a polarização ideológica de meados da década de 1930 e fornece modelos para uma teoria do Estado em que predomina o político sobre o jurídico. O antiliberalismo é um tema corrente na Teoria Política schmittiana e a ele juntam-se a repugnância ao parlamento e a crítica ao contratualismo da democracia. Rodrigues assinala: "A hostilidade em relação à lei ou, mais exatamente, o princípio de que a normatização jurídica dos conflitos sociais é impossível, é uma constante no pensamento de Schmitt” (idem, p. 91). Se não se pode afirmar categoricamente uma ascendência decisiva do pensamento schmittiano sobre os intelectuais d'A Ordem, o mesmo não se pode dizer do maritainismo. É Jacques Maritain e nenhum outro filósofo que exercerá tamanha influência intelectual sobre a revista e sobre o principal líder do laicato católico brasileiro, Alceu Amoroso Lima, sobretudo a partir da década de 1940. Maritain esforçou-se por demonstrar que uma simbiose entre cristianismo e democracia era possível; em uma época em que os totalitarismos à direita eram derrotados (final da II Guerra), essa idéia persuadiu intelectuais como Amoroso Lima a assumirem posturas "mais democráticas”. Em Maritain, planos espiritual e temporal podem ser distintos, mas não separados. Diante dessa questão, se existe na filosofia de Maritain uma "prevalência do espiritual” (idem, p. 100), há, de outro lado, uma acusação dos tradicionalistas de que ele defende a igualdade religiosa ao desenvolver um modelo pluralista do religioso. Porém, “[...] o filósofo se defenderia, alegando que tal acusação seria válida somente se ele tivesse proposto uma igualdade de direitos no plano da verdade religiosa e das crenças, ou seja, no plano espiritual" (idem, p. 107). O que isso quer significar? Minimamente, o fato de Maritain ainda julgar como única verdade religiosa a extraída do catolicismo, muito embora a pluralidade religiosa deva ser aceita e vivenciada como um fenômeno do humanismo cristão.

A partir desses núcleos Rodrigues aprofunda a discussão empírica e testa hipóteses de trabalho. Primeiro, imagina dois pólos teórico-sociológicos que incidem sobre o papel dos intelectuais no Brasil. Expõe as contribuições de Miceli (1979; 2001) e Pécaut (1990) sobre a conduta dos intelectuais durante o varguismo. Estariam eles imbuídos de um "sentido de missão", sem vínculos necessários com os interesses econômico-sociais (Pécaut)? Ou a sedução dos intelectuais pelos empregos públicos e sua dependência diante das autoridades seria uma estratégia para preservar suas posições nas elites dirigentes (Miceli)? Há indícios de que Rodrigues concilia ambas as abordagens. Os intelectuais da década de 1930 caminham em uma tênue linha: entre um "espírito missionário" e entre a cooptação e o apetite pelos cargos e a recuperação de prestígio social. Porém, uma ou outra especificidade dos intelectuais católicos estaria subordinada à influência e à disseminação do pensamento de Maritain. Ao pregar ideais democráticos, o filósofo auxiliaria grande parte da intelectualidade laica a tomar posição contrária à ideologia autoritária presente no varguismo e à prática política pendular do ditador em relação aos fascismos e à democracia.

Na última parte do seu trabalho (RODRIGUES, 2005, p. 138-215), Rodrigues finalmente procede ao estudo da atuação da revista A Ordem entre os anos de 1934 a 1945. O autor procura realizar o que anuncia no preâmbulo. Assim, o trabalho é feito “a partir de uma seleção e análise minuciosa de alguns artigos publicados em suas páginas por diversos intelectuais católicos de renome e influência, que revelam seus posicionamentos 
frente a questões nacionais e internacionais, de ordem política, religiosa, e também cultural. Com esse procedimento", prossegue o autor, "objetivamos, de forma mais específica identificar e analisar de que forma e em que medida a revista incorpora aspectos do ideário conservador em seu discurso, como e porque tais aspectos vão sendo substituídos, gradativamente, por um referencial argumentativo baseado nos postulados da liberdade, pluralidade e democracia. Por fim, a partir dessas questões, analisamos, paralelamente, como a revista se posicionou, ao longo do período estudado, em relação a temas como Liga Eleitoral Católica [LEC], Educação, Comunismo, Liberalismo, Integralismo, Fascismo, Democracia...” (idem, p. 21). A busca pela herança do ideário conservador é, sobretudo, enfatizada pela importância que Rodrigues atribui ao postulado antiliberal d'A Ordem e à crítica corrente dos seus intelectuais ao perigo representado pelo comunismo. São retomadas idéiasforça no seio do pensamento conservador como o anti-individualismo, o culto da unidade e a desigualdade natural entre as classes (idem, p. 146). É paradoxal, no entanto, que o jogo de uma débil democracia é assumido pelos católicos com a fundação da LEC em 1932, organismo suprapartidário e de "aconselhamento", que deveria congregar em suas hostes os políticos católicos sinceros e introduzir no parlamento uma bancada religiosa atuante e defensora dos interesses do catolicismo. Aqui, A Ordem exerceria um papel de ponta, pois, em conjunto com o desempenho dos parlamentares, a revista levantaria bandeiras em torno dos temas mais sensíveis do momento: organização das classes tendo em vista o interesse coletivo (idem, p. 148), combate sem tréguas à Aliança Nacional Libertadora e defesa da Ação Católica (idem, p. 153-167) e a reivindicação por um projeto educacional essencialmente de base católica, com a crítica ao pensamento de John Dewey e aos escolanovistas (idem, p. 168-179). Rodrigues identifica no ano de 1938 um "princípio de mudança” na linha editorial da revista mais devido às rápidas transformações no contexto internacional e menos à realidade interna proporcionada pelo estadonovismo: "Atenta ao avanço do fascismo na Itália e do nazismo na Alemanha às vésperas da Segunda Guerra Mundial [a perseguição à Igreja Católica tanto em um como em outro país, aliada aos fatos internos da sociedade brasileira com a ditadura estadonovista], a revista já não se demonstrava tão reticente quanto antes em relação à atuação desses movimentos no cenário mundial. Apresentava uma posição bem definida de repúdio aos mesmos, já no início de 1938, embora isso não ocorresse de imediato em relação ao governo autoritário no Brasil” (idem, p. 180). Dado esse argumento, o “discurso da liberdade e a opção pela democracia” (idem, p. 192) tem, como origem, não somente a influência da filosofia cristã de Jacques Maritain mas também é objeto "de uma releitura, pontual, das encíclicas papais de Pio XI, fundamentalmente, sobre o fascismo ("Non abbiamo bisogno"), sobre o nazismo ("Mit brennender sorge") e sobre o comunismo ("Divini Redemptoris")" (idem, p. 196). Em princípios dos anos de 1940, a exigência de uma atitude em face dos totalitarismos e a rejeição a qualquer ameaça à liberdade de um país cristão conduziu invariavelmente à denúncia da ditadura do Estado Novo. Mas Rodrigues conclui que, mesmo em face das mudanças observadas, não há como redimir a revista pelo fato "de ter permanecido em silêncio quanto à censura, às perseguições, às prisões, às torturas etc., desencadeadas pelo governo Vargas durante grande parte do período anterior e posterior a 1937" (idem, p. 220).

Algumas considerações críticas sobre a abordagem elaborada por Rodrigues são necessárias. Um dos recortes instigantes do trabalho estabelece-se quanto ao diálogo que o autor propõe desenvolver com os teóricos conservadores e contra-revolucionários, em busca de matrizes inspiradoras da revista A Ordem. Com essa ancoragem no pensamento conservador, torna-se mais evidente que o tipo de posicionamento adotado pelos intelectuais católicos revela sua aversão a intervir junto aos setores populares, optando por uma ação sinérgica e em consonância com as diretrizes da hierarquia eclesiástica, pelo menos durante parte significativa da existência da revista. Em outras palavras, tratava-se de garantir ou consolidar a distância hierárquica própria ao catolicismo institucional da época, demarcando nitidamente a fronteira entre: 1) a multidão de fiéis a ser tipificada no quadro de um catolicismo de orientação romana, trabalho especialmente dirigido pelas ordens religiosas; 2) a multidão a ser "convertida” e 3) os quadros da inteligência católica incumbidos de promover a renovação espiritual da sociedade brasileira, de "cima para baixo". Dessa forma, mais ou menos a partir da década de 1920, os laços com as elites políticas republicanas, inexistentes ou rompidos desde 1889, passaram a ser reatados, ou melhor, constituídos, com vistas a acelerar o processo indicado acima, do qual A Ordem foi um dos esteios.

Em contrapartida, as escolhas teórico-metodológicas do autor, bem como a linha historiográfica proposta pelo trabalho, ao nosso ver carecem de maior precisão. Quando problematizamos o catolicismo institucional brasileiro da primeira metade do século XX, projetamos, essencialmente, uma perspectiva conservadora para o enquadramento do fenômeno. O emprego de expressões como "recristianização", "soberania social de Jesus Cristo”, "integridade católica”; a crítica da liberdade religiosa ou da liberdade de consciência e o repúdio à 
“subversão" são recorrentes no discurso católico, mesmo que esse discurso passe por uma amenização no correr da década de 1930 - exceção feita ao anticomunismo - quando os interesses da Igreja coadunam-se com os interesses do Estado. No entanto, essa análise deve contemplar uma tipologia ou um cruzamento de tipologias. Tornou-se convencional na literatura especializada categorizar a ação e o pensamento da Igreja católica e do laicato, dentro do período avaliado pelo autor, como tributários, em maior ou menor grau, do "ultramontanismo": termo que se torna vago pelo uso abundante, mas que indica, genericamente, uma reação exacerbada da Igreja romana nos séculos XVIII e XIX frente a variados aspectos da sociedade moderna que colocavam em risco o milenar arcabouço doutrinário da instituição e o seu poder social.

Parece que Rodrigues, implicitamente, endossa esse lugar-comum da historiografia, sem se propor a discutir as formas legíveis assumidas por tais percepções quando aplicadas a ambientes culturais cujos interesses e conflitos eram específicos, como no caso brasileiro. Preocupado em demasia com a centralidade do seu objeto, isto é, o papel da intelectualidade e suas representações, Rodrigues não se aprofunda em traçar os limites de subordinação da sua proposta metodológica à categoria "ultramontanismo". Uma consideração similar poderia ser feita quanto aos pontos de aproximação e de distanciamento do grupo laico d'A Ordem em relação à hierarquia eclesiástica, tendo em vista as notáveis mudanças na linha da revista, bem apontadas pelo autor.

Se falamos em “conservadorismo católico”, é recomendável avançarmos para algumas questões: a qual tipo de conservadorismo referimo-nos? Embora investida de crucial importância, é suficiente a conexão direta entre o pensamento conservador europeu e o imaginário da intelectualidade católica brasileira? Se o modelo de funcionamento eclesiástico é "ultramontano", “integrista” ou da "neocristandade”, em que medida tal modelo interage com as permanências e rupturas observadas na linha da revista? Afinal, sabemos, pelo autor, que sob influência do maritainismo e das conjunturas interna e externa A Ordem foi alvo de um processo de "democratização" em suas concepções.

É claro o debate sobre o desempenho da intelectualidade no estadonovismo, assim como são claras as distinções que Rodrigues expõe sobre o tema, sobretudo quando confronta as interpretações elaboradas por Miceli e Pécaut. Porém, não se arrisca a uma definição da categoria "intelectual” e nem se aventura a incursões, breves que sejam, nos textos gramscianos sobre o papel do intelectual. Acabamos intuindo - e desejáramos observá-lo no enfoque de Rodrigues - que o modelo orientador sugerido por Bobbio (1997) poderia servir de diretriz para a classificação dos intelectuais de acordo com determinados critérios: segundo as idéias que sustentam e pelas quais se batem (progressistas ou conservadores; radicais ou reacionários); segundo as ideologias que defendem (liberais ou autoritários; liberais ou socialistas); segundo as atitudes diante das próprias idéias que sustentam (céticos ou dogmáticos; laicos ou clericais).

De modo geral, a abordagem, de fundo mais descritivo do que analítico, permitiu boa clareza dos pressupostos da revista durante o período e de sua respectiva “evolução" temática - antiliberalismo, anticomunismo, restauração, corporativismo, educação religiosa, democracia cristã, liberdade e pluralismo religioso. Permitiu, igualmente, sabermos das dimensão e influência ideológicas d'A Ordem para uma compreensão mais adequada do ethos do intelectual católico e para os desdobramentos do catolicismo brasileiro no período posterior à II Guerra Mundial. A despeito de Rodrigues não ser tão enfático na explicitação de uma linha historiográfica História dos Intelectuais? História Cultural? História Social no entrelaçamento do político e do religioso? esse aspecto não desfavorece o rigor acadêmico e a coerência das argumentações que concernem às prioridades que reserva ao seu objeto. Assim, são raras em trabalhos dessa natureza a fidelidade, a dedicação e a presteza pelas quais o autor defende suas hipóteses. Principalmente para os estudiosos da área, torna-se bastante útil a leitura do texto de Rodrigues. Não somente porque encerra questões situadas entre o passado e o presente que estão inacabadas ou são reelaboradas constantemente, essas questões, sob novos prismas, sob outras condições históricas e renovadas indagações, possibilitam aguçar nossa percepção sobre a dilemática relação entre catolicismo e sociedade. 
Marcos Gonçalves (paideia_mg@yahoo.com.br) é Mestre em História pela Universidade Federal do Paraná (UFPR), doutorando em História na mesma instituição e bolsista do Conselho Nacional de Desenvolvimento Científico e Tecnológico (CNPq).

\section{REFERÊNCIASBIBLIOGRÁFICAS}

ALMEIDA, C. A. 2002. Meios de comunicação católicos na construção de uma ordem autoritária 19071937. São Paulo. Tese (Doutorado em História). Universidade de São Paulo.

BEIRED, J. L. B. 1999. Sob o signo da nova ordem : intelectuais autoritários no Brasil e na Argentina. São Paulo : Loyola.

BOBBIO, N. 1997. Os intelectuais e o poder. Dúvidas e opções dos homens de cultura na sociedade contemporânea. São Paulo : UNESP.

CORDI, C. 1984. O tradicionalismo na República Velha. Rio de Janeiro. Tese (Doutorado em Filosofia). Universidade Gama Filho.

DIAS, R. 1996. Imagens da ordem : a doutrina católica sobre autoridade no Brasil (1922-1933). São Paulo : UNESP.

KANTOROWICZ, E. H. 1998. Os dois corpos do rei : um estudo sobre teologia política medieval. São Paulo : Companhia das Letras.

MICELI, S. 1979. Intelectuais e classe dirigente no Brasil (1920-1945). São Paulo : DIFEL. 1988. A elite eclesiástica brasileira. São Paulo : DIFEL.

2001. Intelectuais à brasileira. São Paulo : Companhia das Letras.

PÉCAUT, D. 1990. Os intelectuais e a política no Brasil : entre o povo e a nação. São Paulo : Ática.

RODRIGUES, C. M. 2005. A Ordem - uma revista de intelectuais católicos (1934-1945). Belo Horizonte : Autêntica.

ROMANO, R. 1994. O pensamento conservador. Revista de Sociologia e Política, Curitiba, n. 3, p. 21-31, nov.

VELLOSO, M. P. 1978. A Ordem : uma revista de doutrina, política e cultura católica. Ciência Política, v. 21, n. 3, p. 117-160, jul.-set. 